\title{
Modeling the Surface Energy Balance of the Core of an Old Mediterranean City: Marseille
}

\author{
A. LEMONSU \\ Centre National de Recherches Météorologiques, Météo-France, Toulouse, France \\ C. S. B. GRIMMOND \\ Atmospheric Science Program, Department of Geography, Indiana University at Bloomington, Bloomington, Indiana \\ V. MASSON \\ Centre National de Recherches Météorologiques, Météo-France, Toulouse, France
}

(Manuscript received 10 February 2003, in final form 4 September 2003)

\begin{abstract}
The Town Energy Balance (TEB) model, which parameterizes the local-scale energy and water exchanges between urban surfaces and the atmosphere by treating the urban area as a series of urban canyons, coupled to the Interactions between Soil, Biosphere, and Atmosphere (ISBA) scheme, was run in offline mode for Marseille, France. TEB's performance is evaluated with observations of surface temperatures and surface energy balance fluxes collected during the field experiments to constrain models of atmospheric pollution and transport of emissions (ESCOMPTE)-urban boundary layer (UBL) campaign. Particular attention was directed to the influence of different surface databases, used for input parameters, on model predictions. Comparison of simulated canyon temperatures with observations resulted in improvements to TEB parameterizations by increasing the ventilation. Evaluation of the model with wall, road, and roof surface temperatures gave good results. The model succeeds in simulating a sensible heat flux larger than heat storage, as observed. A sensitivity comparison using generic dense city parameters, derived from the Coordination of Information on the Environment (CORINE) land cover database, and those from a surface database developed specifically for the Marseille city center shows the importance of correctly documenting the urban surface. Overall, the TEB scheme is shown to be fairly robust, consistent with results from previous studies.
\end{abstract}

\section{Introduction}

Many studies have documented aerodynamic and thermodynamic perturbations induced by cities on localscale climates (see, e.g., Cleugh and Oke 1986; Grimmond 1992; Grimmond and Oke 1995, 1999a; Roth and Oke 1995; Oke et al. 1999; Christen et al. 2002; Offerle et al. 2002; Rotach 2002). The 3D geometry of the urban surface, the properties of the artificial materials used for construction, and the anthropogenic emissions (Oke 1987) all have been shown to have an important influence on radiative and surface energy balance (SEB) fluxes, resulting in important differences in surface-atmosphere exchanges between and within cities.

Numerical weather prediction models have only recently included urban areas explicitly in the surface schemes (Bornstein 1975; Best 1998; Taha 1999; Brown

Corresponding author address: A. Lemonsu, Météo-France, CNRM/GMME/MC2, 42 av G. Coriolis, 31057 Toulouse Cedex, France.

E-mail: aude.lemonsu@cnrm.meteo.fr
2000; Martilli et al. 2002). Very different approaches are employed to describe and model the urban surface, ranging from simple approaches that consider a city as a concrete layer (Best 1998), to more detailed representations of the materials and morphology of the urban surface (Masson 2000; Martilli et al. 2002) that can capture the local-scale spatial variability of fluxes known to occur.

Here, the local-scale energy and water exchanges between urban surfaces and the atmosphere are parameterized using the Masson (2000) Town Energy Balance (TEB) scheme, coupled with the Noilhan and Planton (1989) Interactions between Soil, Biosphere, and Atmosphere (ISBA) scheme. The latter is used for the vegetated areas (more details in section 3). In this study, attention is directed to TEB-ISBA's ability to reproduce the fluxes, and to the influence of surface input data. Previously, TEB has been evaluated offline for Mexico City, Mexico, and Vancouver, British Columbia, Canada (Masson et al. 2002), and coupled to the nonhydrostatic mesoscale atmospheric model (Méso-NH; Lafore et al. 


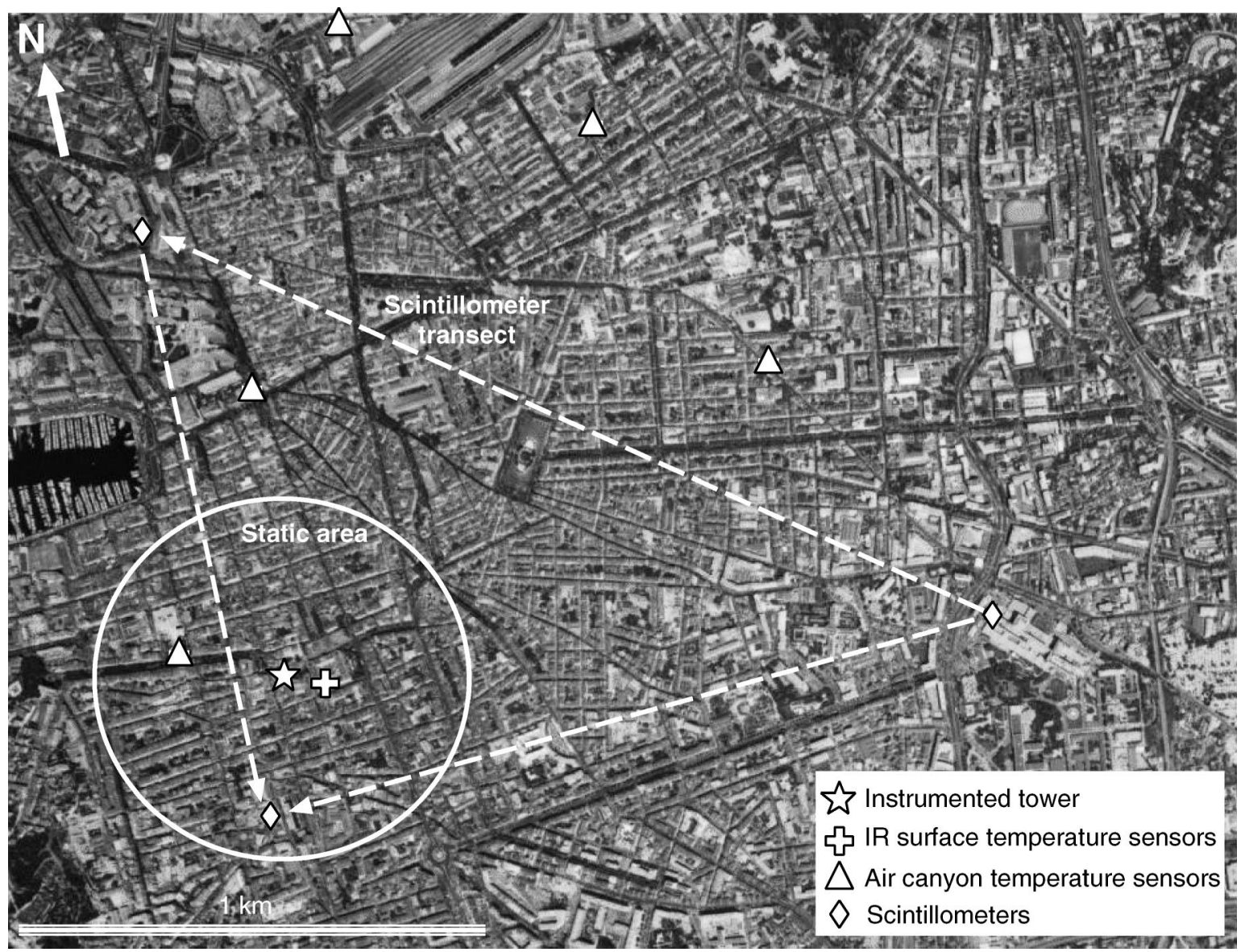

FIG. 1. Aerial photograph of Marseille city center (provided by M. A. Velay-Dabat, Ecole d'Architecture de Marseille-Luminy) showing the location of the instruments.

1998) for Paris, France (Lemonsu and Masson 2002). Here, TEB is applied to the dense city center of Marseille, France (Fig. 1), and its performance is evaluated with observations collected during the field experiments to constrain models of atmospheric pollution and transport of emissions (ESCOMPTE)-urban boundary layer (UBL) campaign (Cros et al. 2002; Mestayer et al. 2003).

\section{Field measurements}

ESCOMPTE involved an extensive field campaign to study and evaluate the emission and transport of chemical species and atmospheric pollution in the MarseilleBerre region of the south of France (Cros et al. 2002). The study area is composed both of an industrial site (around Berre Pond) and the dense urban area of Marseille [see the map of the study domain in Cros et al. (2002)]. The proximity of the Mediterranean Sea and the mountains surrounding the region make the geographic setting extremely complex. Coupled to ESCOMPTE, the UBL program (Mestayer et al. 2003) documented radiative surface temperatures, surface en- ergy balance fluxes, and the 4D structure of the boundary layer of the city of Marseille.

ESCOMPTE-UBL took place during the summer of 2001, from 4 June to 16 July. The summer climate in this region is sunny, with maximum air temperatures about $30^{\circ}-35^{\circ} \mathrm{C}$ inland and $25^{\circ}-30^{\circ} \mathrm{C}$ on the coast. Sea breezes are common and are best developed in the afternoon, blowing mainly from the southwest over Marseille. Mistral (strong northwest winds) and southeast winds also affect the city. These three different wind regimes have important influences on heat flux partitioning in the city (Grimmond et al. 2002).

In this paper, TEB-ISBA is evaluated for the downtown $\left(43^{\circ} 17^{\prime} \mathrm{N}, 5^{\circ} 22^{\prime} \mathrm{E}\right)$ core of Marseille. During ESCOMPTE-UBL, a pneumatic tower was installed on the roof of the Administrative Court of Appeal of Marseille (CAAM; Grimmond et al. 2002). The data collected at this site included temperature, humidity, wind speed, pressure, upward and downward global short- and longwave radiation, and the surface energy balance fluxes. The turbulent sensible $\left(Q_{H}\right)$ and latent $\left(Q_{E}\right)$ heat fluxes were determined by the eddy covariance method, while the heat storage $\Delta Q_{S}$ was determined as the residual 
term of the SEB $\left[\Delta Q_{S}=Q^{*}-\left(Q_{H}+Q_{E}\right)\right.$, where $Q^{*}$ is the net all wave radiation]. The SEB data used in this study are from the upper of two levels on the tower$43.9 \mathrm{~m}$ above ground level (AGL) under light wind conditions, and $34.6 \mathrm{~m}$ under strong wind conditions. Grimmond et al. (2002) demonstrate that these measurements are representative of the local scale in both cases. Other data used in the analyses include the following:

- albedo measurements from material representative of Marseille (T. R. Oke, University of British Columbia, 2002, personal communication);

- external surface temperatures for roads, roofs, and walls for streets around CAAM (J. A. Voogt, University of Western Ontario, 2002, personal communication; T. R. Oke and S. M. Roberts, University of British Columbia, 2002, personal communication; surface temperatures for streets with different orientations, along with tile and gravel roofs were studied);

- internal building (wall) temperatures in buildings without air conditioning (J. A. Voogt and T. R. Oke 2002, personal communication);

- sensible heat fluxes measured by scintillometry using the free-convection method along three transects (Fig. 1) (Lagouarde et al. 2002); and

- a network of 20 temperature and relative humidity sensors located in the middle of streets (Pigeon et al. 2002). [Instruments were mounted approximately $6 \mathrm{~m}$ AGL, and were located as far as possible away from walls, to minimize the effects of shaded or sunlit surfaces. Five of these instruments were located in the city core, close to the tower (see Fig. 1).]

\section{Numerical schemes}

The models used are the TEB and ISBA (Noilhan and Planton 1989) schemes. These models parameterize the exchanges between artificial surfaces and the atmosphere, and between natural surfaces and the atmosphere, respectively.

The TEB scheme, described in Masson (2000), represents the city as an ensemble of urban canyons (Oke 1987). Some improvements were conducted and are presented in this section. To ensure that these modifications are not just connected to the specific nature of the Marseille city center, simulations from Mexico City and Vancouver, previously presented in Masson et al. (2002), were rerun by applying the new parameterizations (see appendix A).

Surface temperatures are resolved for each of the three urban surfaces modeled: roads, roofs, and walls. In order to account for heat conduction into artificial materials, the roofs, roads, and walls are represented in terms of several layers, as shown on Fig. 2 (in this work four layers are used). The materials, their thermal properties, and the thickness of the layers are input parameters to TEB. In TEB, the individual wall and road SEB

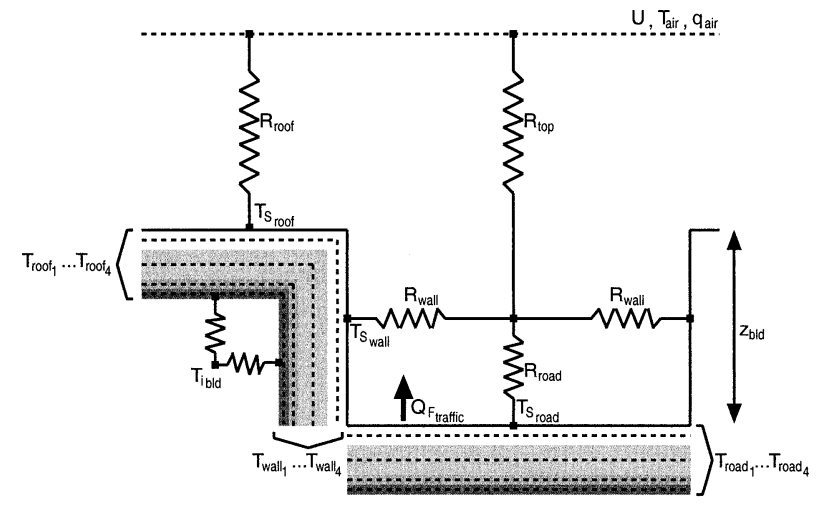

FIG. 2. The TEB scheme.

and surface temperatures are weighted to yield the top of the canyon SEB and canyon air temperature for the middle of the street (see further discussion in Masson et al. 2002) via the aerodynamic resistances (see Fig. $2)$, according to

$$
T_{\text {can }}=\frac{\frac{T_{S_{\text {road }}}}{R_{\text {road }}}+\frac{2 z_{\text {bld }}}{W} \frac{T_{S_{\text {wall }}}}{R_{\text {wall }}}+\frac{T_{\text {air }}}{R_{\text {top }}}+\frac{Q_{F_{\text {traffic }}}}{C_{\mathrm{pd}} \rho_{a}\left(1-f_{\text {roof }}\right)}}{\frac{1}{R_{\text {road }}}+\frac{2 z_{\text {bld }}}{W} \frac{1}{R_{\text {wall }}}+\frac{1}{R_{\text {top }}}},
$$

where $C_{\mathrm{pd}}$ is air heat capacity and $\rho_{a}$ is air density; $f_{\text {roof }}$ is the roof fraction, $z_{\mathrm{bld}}$ is the mean building height, and $W$ the mean width of the streets; $Q_{F_{\text {traffic }}}$ is the sensible heat flux due to traffic; $T_{S_{\text {road }}}, T_{S_{\text {wall }}}$, and $T_{\text {air }}$ are the road and wall surface temperatures and air temperature above the canyon, respectively; $R_{\text {road }}$ and $R_{\text {wall }}$ are the aerodynamic resistances between the canyon surfaces and the air inside the canyon; $R_{\text {top }}$ is the resistance between the air inside the canyon and above the roof level; and $R_{\text {wall }}$ depends on $U_{\text {eff }}$, a typical wind speed inside the canyon:

$$
R_{\mathrm{wall}}=C_{\mathrm{pd}} \rho_{a}\left(11.8+4.2 U_{\mathrm{eff}}\right)^{-1}
$$

where

$$
U_{\text {eff }}=\sqrt{U_{\text {can }}^{2}+\left(u_{*}+w_{*}\right)^{2}} .
$$

Here, $U_{\text {eff }}$ is a combination of the mean wind in the canyon $U_{\text {can }}$ and of the turbulent wind $u_{*}+w_{*}$. Note that the initial formulation of $U_{\text {can }}$ (Masson 2000) is now extended to the wake interference flow and the isolated roughness flow (Oke 1987). This modification, presented in appendix B, has no impact for Marseille's city center, where a skimming flow is expected because of the high aspect ratio values. The dynamical turbulent term $u_{*}$ was already taken into account in the Masson (2000) version of TEB. However, given the hot conditions in Marseille in June, the free-convection velocity $w_{*}$ was added. This term comes from the Monin-Obukhov similarity theory (1954). It assumes that the thermal production of turbulence is not negligible. Here, the 
general formulation of $w_{*}$ is only applied to the building height instead of using the boundary layer height:

$$
w_{*}=\left(\frac{g}{T_{\text {can }}} Q_{0} z_{\mathrm{bld}}\right)^{1 / 3},
$$

where $Q_{0}$ encompasses both road and wall turbulent heat fluxes. This new parameterization increases the aerodynamic conductance, which favors heat extraction from the canyon surfaces.

The other aerodynamic resistances depend on the stability inside or above the canyon (Masson et al. 2002):

$$
\begin{aligned}
R_{\text {road }} & =f\left(\mathrm{Ri}, z_{\text {bld }} / 2, U_{\text {eff }}, z_{0_{M} \text { road }}, z_{0_{H} \text { road }}\right) \text { and } \\
R_{\text {top }} & =f\left(\mathrm{Ri}, z_{\text {ref }}, U, z_{0_{M} \text { town }}, z_{0_{H} \text { cany }}\right),
\end{aligned}
$$

where $z_{\text {ref }}$ is the distance between the top of the roofs and the top of the tower, where the measurements were made. It defines the atmospheric forcing level; $\mathrm{Ri}$ is the Richardson number (either between the road surface and canyon, or canyon and above-canyon atmosphere), and $U$ is the horizontal wind at $z_{\text {ref }}$. Respectively, $z_{0_{M} \text { road }}$ and $z_{0_{H_{\text {road }}}}$ are the roughness lengths for momentum and heat for the road surface. For the local-scale urban area, $z_{0_{M} \text { town }}$ is the roughness length for momentum, and $z_{0_{H} \text { cany }}$ is the roughness length for heat for the canyon. An aerodynamic resistance is also associated with the roofs:

$$
R_{\text {roof }}=f\left(\mathrm{Ri}, z_{\text {ref }}, U, z_{0_{M_{\text {roof }}}}, z_{0_{H_{\text {roof }}}}\right) .
$$

In TEB, the road and wall dynamic roughness lengths are fixed to 0.05 and $0.15 \mathrm{~m}$, respectively, while $z_{0_{M} \text { town }}$ depends on the site. The equivalent thermal roughness lengths are deduced by applying a constant ratio between the dynamic and the thermal roughness lengths. Voogt and Grimmond (2000) find values between $10^{6}$ and $10^{11}$ for urban surfaces. In TEB, the road and roof heat roughness lengths were equal to $2.5 \times$ $10^{-4}$ and $7.5 \times 10^{-4} \mathrm{~m}$, and $z_{0_{H} \text { cany }}$ was calculated as the ratio $z_{0_{M} \text { town }} / 200$ [the ratio of 200 is the mathematical maximum limit accepted for the equations of Mascart et al. (1995), which approximate the Monin-Obukhov equations in the TEB and ISBA schemes]. However, analyses done in the present study showed that for the canyon resistance network (see section 6a), this ratio must be applied only between the individual surfaces and the air, not between the canyon air and the atmosphere. The new formulations express that heat is extracted with great difficulty from the artificial surfaces; but once the heat has been released, it can be freely vented by turbulence, in particular, from the canyon to the atmosphere. This process has been demonstrated experimentally by Barlow and Belcher (2002).

Even if $z_{0_{H} \text { cany }}$ is set to the same value as $z_{0_{M} \text { town }}$ to represent the high ventilation, the ratio between $z_{0_{M}}$ and $z_{0_{H}}$ for the overall city remains large. For medium- to high-density urban areas, $z_{0_{M} \text { town }}$ is usually on the order of $1 \mathrm{~m}$ (Grimmond and Oke 1999b); $z_{0_{H} \text { town }}$ depends on

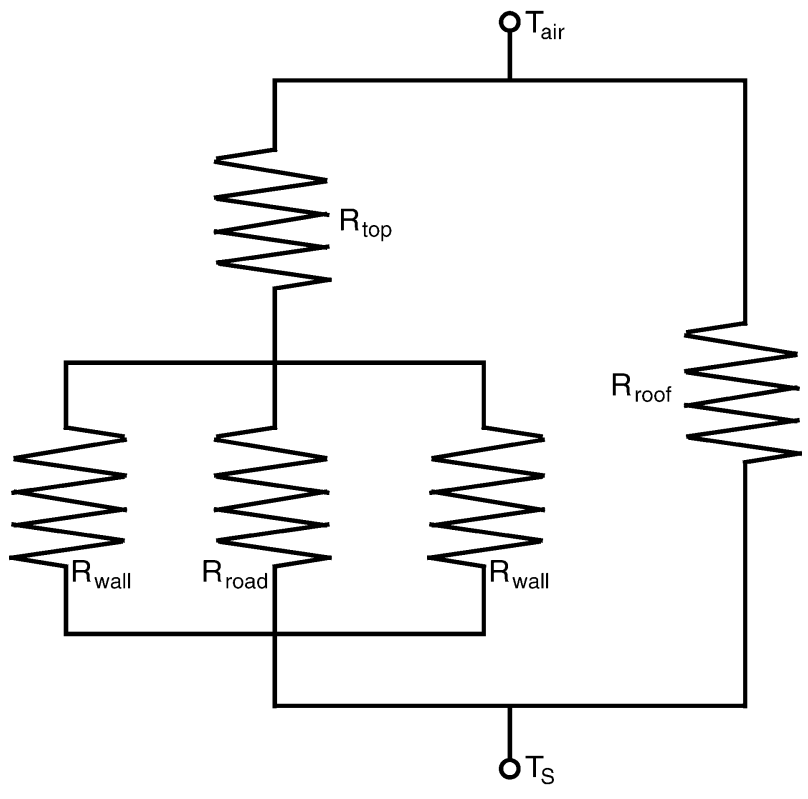

FIG. 3. Ideal aerodynamic resistance network.

the thermal roughness length of the roofs and of the canyon system. In a simple approach, if $T_{S_{\text {roof }}}, T_{S_{\text {wall }}}$, and $T_{S_{\text {road }}}$ are assumed equal, and if the surfaces are in similar proportions, the resistance network presented on Fig. 2 is equivalent to an ensemble of resistances put in series and parallel according to the system of Fig. 3, then, this can be substituted by an equivalent resistance. Given that $R_{\text {top }}$ is negligible in comparison with $R_{\text {wall }}$ and $R_{\text {road }}$, the expression of the global resistance $R_{\text {eq }}$ is written as

$$
R_{\text {eq }}=\frac{R_{\text {roof }} R_{\text {road }} R_{\text {wall }}}{R_{\text {road }} R_{\text {wall }}+R_{\text {roof }} R_{\text {wall }}+2 R_{\text {roof }} R_{\text {road }}} .
$$

Note that $R_{\text {wall }}$ is of the same order of magnitude as $R_{\text {road }}$, even if it is not computed with a roughness length formulation [see Eq. (2)], because heat is also difficult to extract from walls. Consequently, the value of $R_{\text {eq }}$ is of the same order of magnitude as $R_{\text {roof }}, R_{\text {road }}$, and $R_{\text {wall }}$. In the same way, the values of thermal roughness length are comparable and the order of magnitude of $z_{0_{H} \text { town }}$ is $10^{-4} \mathrm{~m}$. Under real conditions, the surface temperatures are different for roads, roofs, and walls, and the relative fractions of each surface may vary (e.g., the wall resistance will have less importance if there are less walls). Nevertheless, the resistance network is close to the ideal system presented previously and the $z_{0_{H} \text { town }}$ can be assumed to be of the same order of magnitude, that is, $10^{-4} \mathrm{~m}$.

The ISBA scheme resolves the SEB for the natural surfaces in the modeling domain. It is presented in detail in Noilhan and Planton (1989). ISBA has been evaluated against surface energy balance flux observations for Field Experiments in a Desertification-Threatened Area (EFEDA) and the Hydrological Atmospheric Pilot Ex- 
periment (HAPEX)-Modelisation du Bilan Hydrique (MOBILHY) field experiments (Noilhan and Mahfouf 1996).

\section{Characterization of Marseille's city center}

Both TEB and ISBA schemes need an accurate description of the surface. For 3D modeling, the TEBISBA parameters are usually derived from the Coordination of Information on the Environment (CORINE) land cover classification (CEC 2000), according to Masson et al. (2003). Here, an independent, detailed database was developed to define the parameters for the Marseille city center. This database included a land cover map, geometric parameters of the streets, and thermal properties of building and road materials. To create this surface database, an aerial photograph of the downtown area of Marseille (Fig. 1) was used to determine average surface cover of 11 major surface cover types for a $1000-\mathrm{m}$ radius area around the tower. Four kinds of roof (tile, gravel, white, and other roofs), with distinct thermal and radiative properties, were distinguished. Roads and courtyards were distinguished in terms of surface cover: asphalt, concrete, and gravel. Natural cover classes consisted of trees, other vegetation, water, and bare ground. A 2-m-horizontal-resolution database of building heights was developed independently by Long et al. (2002), based on data of the French National Geographic Institut (IGN).

The French Electricity Company (EDF), and the Atelier du patrimoine de la ville de Marseille (1983) provided information on the most common construction methods in the southeast of France. These were used to define the materials used for roofs, roads, and walls, and the thicknesses of different layers. The thermal properties of these materials were defined using typical values from the literature (ASHRAE 1981; Oke 1987; McMullan 1992; Mills 1993). Albedos were measured for new tile and gravel roofs $(0.28$ and 0.21 , respectively) and were estimated from literature for old tile darker roofs (0.15). The latter account for about 50\% of the tile roof area.

The roughness length for momentum was estimated as $1.9 \mathrm{~m}$, based on measured turbulence data.

\section{Simulation}

A modeling domain, corresponding to a specific area of the Marseille city center, had to be chosen for comparison against the observed fluxes. Two different approaches can be used: static and dynamic. The static approach assumes that the surface characteristics around the study site are quite homogeneous. A circular area, centered on the measurement point, is defined and surface parameters calculated. The dynamic approach takes into account the variable "source areas" of turbulent flux measurements (Schmid and Oke 1990; Grimmond
TABLE 1. Cover fractions, TEB, and ISBA input parameters initialized for the static modeling domain (a 500-m radius circle around the tower site).

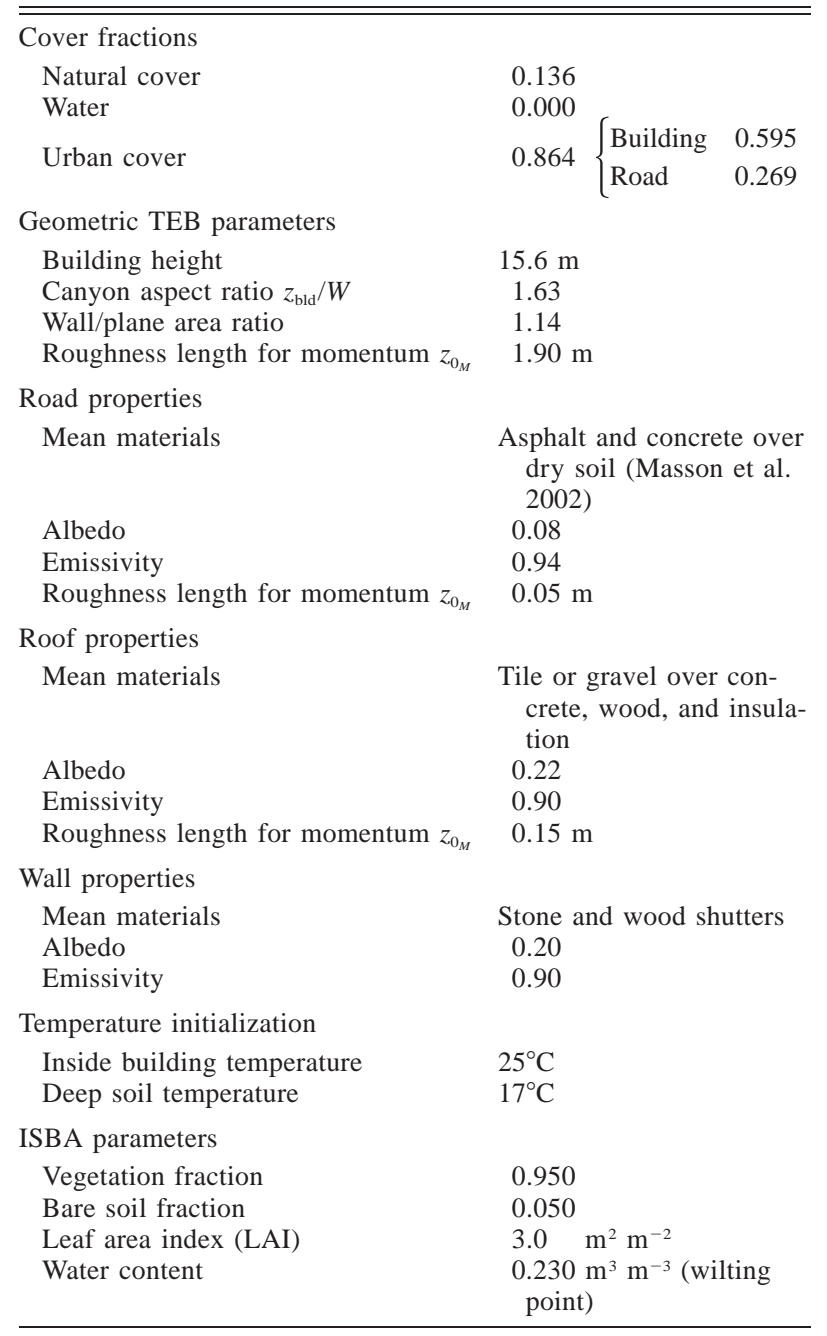

and Oke 1991) as a function of changing wind and stability conditions.

First, the modeling domain was defined for a static 500-m radius circle centered on the tower (Fig. 1). Table 1 presents all of the input parameters computed for this domain. For example, the roof albedo is calculated as the average of the new tile, old tile, and gravel albedos, according to their respective fractions. An anthropogenic sensible heat flux, $Q_{F}$, is included in the model simulations in order to take into account the traffic in Marseille. Because no measurements were available to evaluate this term, a typical daily cycle of $Q_{F_{\text {traffic }}}$ was added, following Grimmond (1992). Estimates of $Q_{F_{\text {tutfic }}}$ from this simple approach are always less than $15 \mathrm{~W} \mathrm{~m}^{-2}$ in the day and $2 \mathrm{~W} \mathrm{~m}^{-2}$ at night.

The TEB and ISBA models are run in offline mode. Both old and new versions of TEB are tested to study the impact of the modifications. The data collected at the top of the tower are used directly to force the 


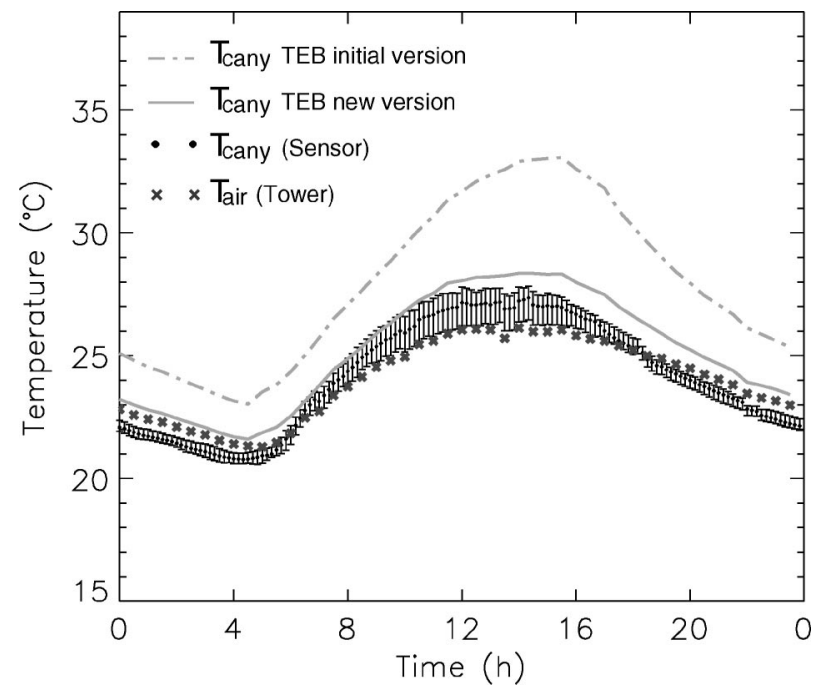

FIG. 4. Comparison between observed and simulated canyon air temperature, averaged for 21 days. The vertical bars are the maximum bias of observed mean canyon temperature between the different sensors. The tower air temperatures are recorded above the roof level at the top of the tower.

schemes with a 30-min time step. The forcing level in the model varies between 43.9 and $34.6 \mathrm{~m}$, consistent with the (up or down) position of the tower (Grimmond et al. 2002). Data for the third intensive observation period (IOP 3; 2-4 July), are not included here because they are being withheld for a blind test of the dynamic and chemistry models (Cros et al. 2002). Because the models are forced by the observations, two independent simulations had to be done: 14 days (from 18 June to 1 July) before IOP 3 and 7 days (from 5 to 11 July) after. The results obtained by the static approach are presented in the next section. It is followed by a sensitivity study of the surface characteristics (section 7a).

\section{Results}

\section{a. Canyon air temperature}

This is the first evaluation of TEB where modeled canyon air temperatures can be compared with observations (Pigeon et al. 2002). Given that vegetation cover is limited in downtown Marseille, the TEB-modeled temperature, for the top of the center of the canyon, is compared directly with the average temperature from five in-canyon stations in the city's center (Fig. 1). These results, and those for the above roof temperature, are presented in Fig. 4. The vertical bars show the variability of observed canyon temperatures. In the initial simulation, the resolved canyon temperature overestimates the observations by $4^{\circ} \mathrm{C}$ during the night and by much more during the day (between $6^{\circ}$ and $10^{\circ} \mathrm{C}$ ). The observations show that the difference between canyon temperature and above-the-roof-level air temperature is small, while the road and the walls around the sensor are much warmer (surface temperatures are presented in the next section). Mixing of air takes place in the upper part of the canyon and explains the influence of the atmosphere temperature on the canyon temperature.

Much urban canyon research has focused on dynamic processes in canyons, especially in the context of understanding dispersion of pollutants (Johnson and Hunter 1995; Baik and Kim 2002). Many studies show the development of a vortex inside the canyon, which is related both to the flow above the roof level, and the canyon geometry. Other studies have been concerned with the role of thermal processes inside street canyons. Experimentally, Nakamura and Oke (1988) found large temperature differences between the air inside the street and the sunlit building surfaces (about 12-14 K) but small differences between the air in the middle and at the top of the canyon (almost always less than $1 \mathrm{~K}$ ). Vachon (2001) obtained similar results for a street canyon with a 1.4 aspect ratio during summer with lowwind conditions. Kim and Baik's (1999) simulation of the $2 \mathrm{D}$ potential temperature field inside a canyon with one heated building face found a large temperature gradient close to the heated surface and a lower air temperature in the middle of the street. As noted in section 3, Barlow and Belcher (2002) show that the aerodynamic resistance between the canyon and the atmosphere above the street is very small.

As presented in section 3, previous formulations of TEB did not produce sufficiently rapid ventilation of the heat released by the urban surfaces inside the canyons. With the new version of the canyon resistance, the predictions of TEB agree much more closely with the observations, although temperatures are consistently overestimated by $2 \mathrm{~K}$. The canyon air temperature varies slightly from one station to another, influenced by the distance to the coastline, vegetation close to the sensor, the aspect ratio of the street, and the exact nature of the buildings.

\section{b. Surface temperature}

In the TEB scheme, long- and shortwave radiation balances are resolved by integration across all the street orientations (Masson 2000). One mean surface temperature is calculated for each kind of surface: $T_{\text {Sroad }}$ $T_{\text {Sroof }_{\mathrm{TEB}}}$, and $T_{\text {Swall }_{\mathrm{TEB}}}$. In the ESCOMPTE-UBL campaign, sensors were installed in different locations in the area around the tower (see section 2). Diurnal patterns vary in response to the specifics of each site. To compare these observations with the surface temperatures resolved by the model, the average $T_{S_{\text {road }} \text { obs? }}$, $T_{\text {Sroof }_{\text {obs }}}$, and $T_{S \text { wall }_{\text {obs }}}$ have to be calculated according to the street orientations. The fractions of the roofs composed of tile and gravel fractions are accounted for in the computation of the mean roof surface temperature (see Table 2). The results of the comparison of mean observed and modeled surface temperatures are presented in Fig. 5 and Table 3. 
TABLE 2. Sites used to calculate the mean surface temperatures, including the number of sensors, the characteristics, and the number of days of data available. Source of data: J. Voogt, University of Western Ontario.

\begin{tabular}{|c|c|c|c|c|c|}
\hline & Roads & Walls & & Roofs & \\
\hline \multirow{3}{*}{$\begin{array}{l}\text { No. of sites } \\
\text { Site }\end{array}$} & 3 & 4 & 5 & 4 & 3 \\
\hline & 1 east-west & 1 north +1 south & 1 gravel roof & 1 gravel roof & 1 gravel roof \\
\hline & +2 north-south & +1 east +1 west & +4 tile roofs & +3 tile roofs & +2 tile roofs \\
\hline No. of days & 13.3 & 9.8 & 2.3 & 3.0 & 1.0 \\
\hline
\end{tabular}

The best results are obtained for the roof surface temperature, which is modeled well, both in terms of magnitude and timing. For the roads and the walls, the comparison shows a good agreement at night but an overestimation of the maximum surface temperature during the day (with a maximum error of about 2 or $3 \mathrm{~K}$ ). The new parameterization of the road and wall aerodynamic conductances (presented in section 3) improved results, especially for the road surface temperature, where the bias with the initial version of TEB was more than 6 K. Despite this improvement, the simulated road and wall surface temperatures remain offset from the observations, with different daily cycles. Some of this may be due to fact that the observations were conducted in narrow streets with aspect ratios of about 2 , whereas for the model simulation an aspect ratio of 1.6 (Table 1 ) is used. The modeling domain has both narrow (colder) and large (warmer) streets (Fig. 1). Unfortunately, only three road surface temperature sites were available: two inside east-west streets and one inside a north-south street (see Fig. 5).

For the walls, more measurements are available, but there was high variability observed between the sites (see Fig. 5) - a function of the pattern of the buildings, the canyon orientation, and the width of the streets, which all influence when surface heating starts to occur on roads and walls. To more fully evaluate TEB's ability to reproduce aggregate road and wall temperatures, a more complete sampling of street orientations will be needed. Remotely sensed data have the advantage of giving more complete spatial coverage, which may correspond more appropriately to the model domain. However, such data tend to be temporally limited and do not necessarily see all of the facets (Masson et al. 2002).

On the whole, the temperature results are considered satisfactory for the three surfaces considered, due in part to the improvement of the ventilation process resulting from greater understanding of canyon temperatures.

\section{c. Internal building temperature}

Internal building temperatures were recorded during the campaign at four sites. The sensors were located on the internal wall or about $0.1 \mathrm{~m}$ from the wall. These measurements were averaged and compared with the temperature of the wall internal layer resolved by TEB, according to Masson et al. (2002).

The modeled temperature is always cooler than the observed internal temperature, and the magnitude of its diurnal cycle is larger (Fig. 6). A maximum bias of about $3 \mathrm{~K}$ is observed at $0800 \mathrm{UTC}$. The value of the air temperature inside the room defined by TEB appears to be to low. However, a sensitivity test of this term shows no major impact on the surface temperatures presented in the previous section or on the radiative and energetic fluxes.


FIG. 5. Comparison between observed and simulated road, wall, and roof surface temperatures. The black thin lines represent all of the measurements, while the asterisks present the mean observed surface temperatures weighted by street orientation. The gray lines represent the composite surface temperatures resolved by TEB. 
TABLE 3. Performance statistics for road, wall, and roof surface temperatures $(\mathrm{K})$.

\begin{tabular}{lcc}
\hline \hline & Bias $($ TEB - obs $)$ & Rmse \\
\hline$T_{\text {road }}$ & +2.2 & 3.8 \\
$T_{\text {wall }}$ & +0.9 & 1.6 \\
$T_{\text {roof }}$ & -0.3 & 2.1 \\
\hline
\end{tabular}

\section{d. Radiative fluxes}

The incoming and outgoing global short- and longwave radiation fluxes were recorded near the top of the tower. Both incoming long- $\left(L^{\downarrow}\right)$ and shortwave $\left(S^{\downarrow}\right)$ radiation are used to force the surface schemes (see section 5). The fraction of incident radiation absorbed by built and natural surfaces is computed by TEB (separately for roads, walls, and roofs) and ISBA. Both short- and longwave upward-simulated radiation, weighted according to natural and built surface fractions, are compared with the observations in Fig. 7. In addition, an averaged simulated albedo, determined from the natural cover albedo (ISBA initial parameter) and the global urban albedo, is compared with the measured one (not shown). The albedos of each urban surface and the geometric parameters of the canyon are used to calculate the global urban albedo (see appendix C). In particular, the comparison of the averaged albedo allows an evaluation of the computation of the trapping effect by reflections.

The upward shortwave radiation is simulated well by TEB-ISBA, and the mean daily albedo (about 0.14, according to the outputs) is in good agreement with measurements $(0.160$ when the tower is at $43.9 \mathrm{~m})$. Nevertheless, a slight underestimation is evident in the morning: the diurnal cycle of observed radiation presents higher radiation values in the morning than in the afternoon, while the simulated cycle is perfectly symmetric because the TEB scheme calculates the radiative balance by using an ideal symmetric canyon. Sensitivity analyses show that a strong trapping of shortwave radiation occurs in the canyon (canyon albedo is around 0.04, not shown). For deep canyons, TEB is not sensitive to wall and road albedos. It is much more sensitive to roof albedo.

The upward longwave radiation is slightly overestimated by TEB. Given the geometric parameter values used for Marseille, most upward radiation comes from the roofs. Given the high aspect ratio of the street canyons, the walls play a more important role than the roads in the radiative balance. Here, about $50 \%$ of the bias of upward longwave radiation is apparently due to a toohigh emission from the walls, where the surface temperature is overestimated by TEB (see section $6 \mathrm{~b}$ ).

\section{e. Surface energy fluxes}

The flux measurements recorded at the top of the tower are compared with the averaged energy fluxes

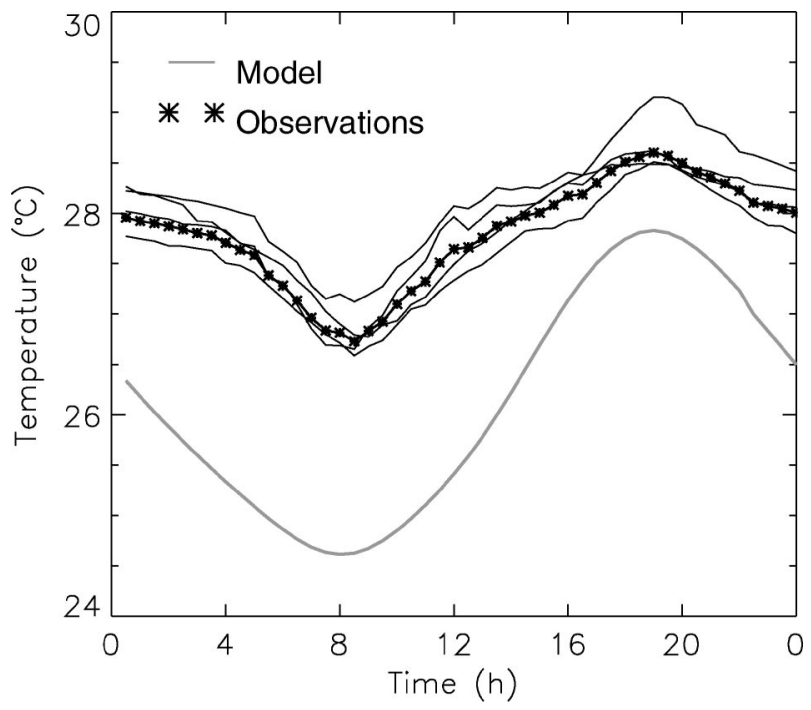

FIG. 6. Comparison between observed and simulated internal building temperatures. The black thin lines represent all the measurements, while the asterisks present the weighted mean observed temperature.

computed by the TEB-ISBA model (Fig. 8). The bias and root-mean-square errors (rmse) for the overall, nighttime, and daytime periods are given in Table 4. Generally, the agreement between the modeled and measured SEB fluxes is good, with a bias of around 10-30 $\mathrm{W} \mathrm{m}{ }^{-2}$, regardless of the period considered. During the day $Q^{*}$ is underestimated because of the longwave radiation bias presented in the previous section. Also $Q_{H}$ is underestimated. This may be connected to a lack of mixing at the roof level. Nevertheless, the model succeeds in producing a positive sensible heat flux at night,

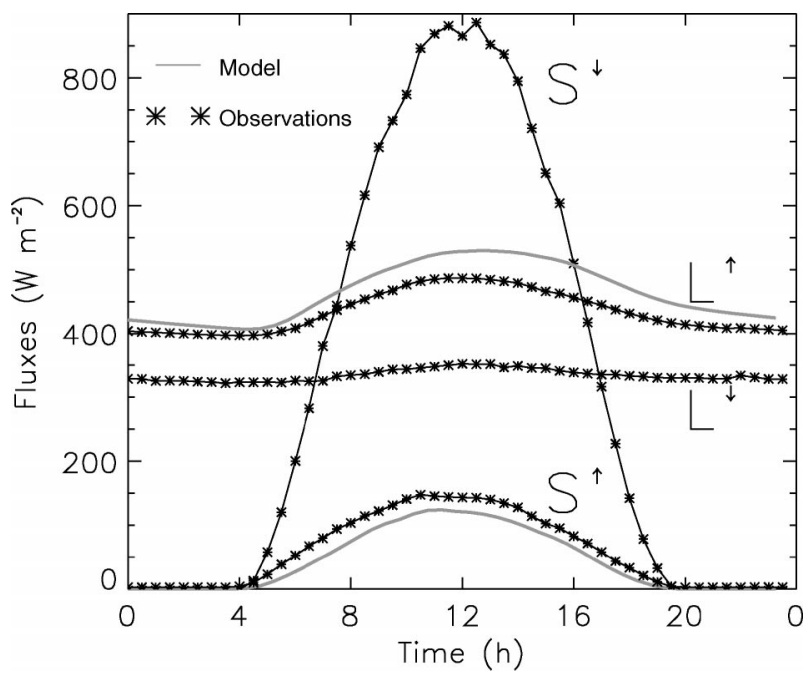

FIG. 7. Comparison between observed and simulated radiative fluxes. The black asterisks represent the observed incoming and outgoing solar $\left(S^{\downarrow}\right.$ and $\left.S^{\uparrow}\right)$ and longwave $\left(L^{\downarrow}\right.$ and $\left.L^{\uparrow}\right)$ radiation recorded at the top of the tower. The gray lines represent the simulated outgoing solar and longwave radiation average according to surface fractions. 

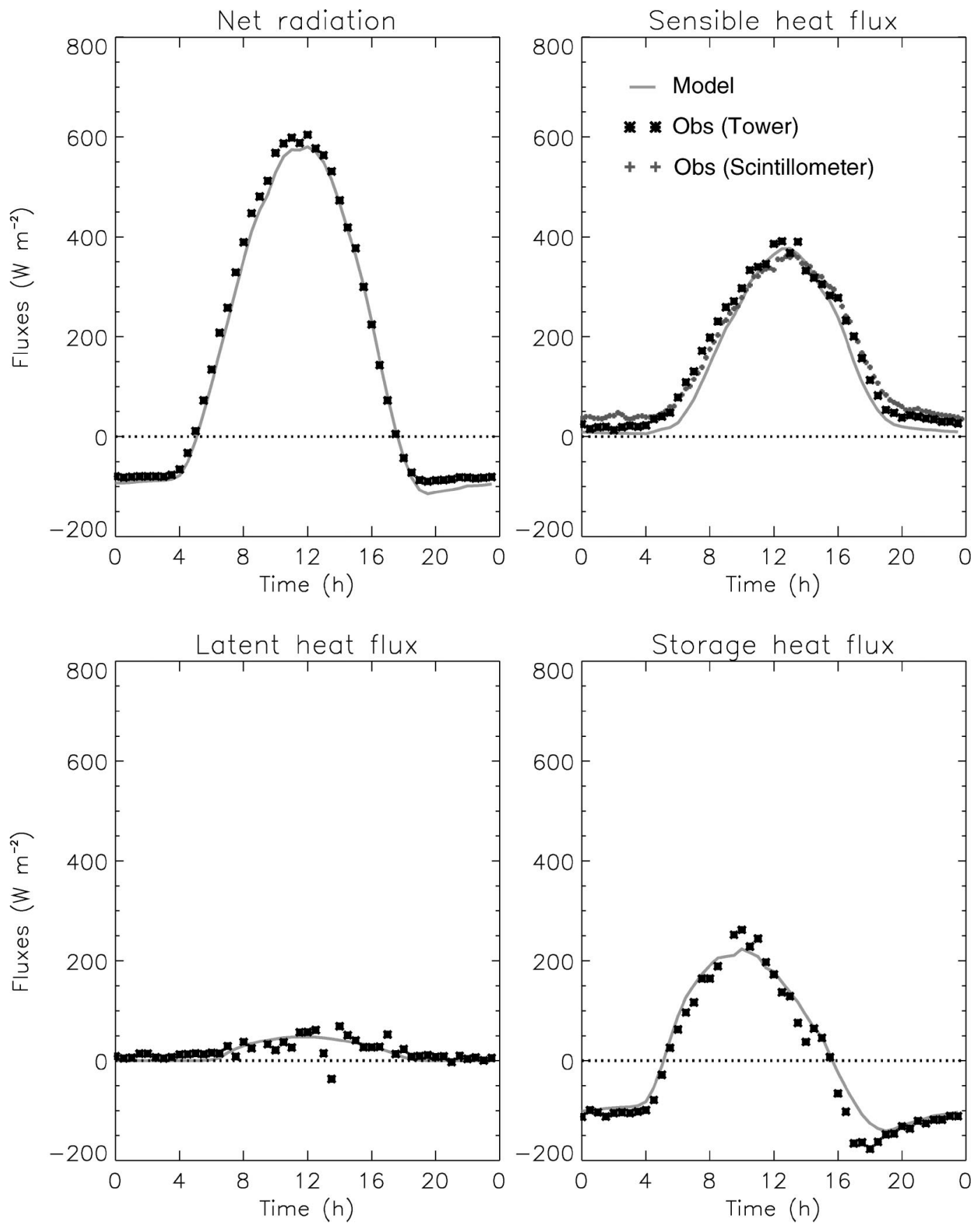

FIG. 8. Comparison between observed and simulated surface energy balance. The black asterisks are the observed fluxes at the top of the tower. The gray pluses are sensible heat flux calculated from the scintillometer data, according to the free-convection method. The gray line is the simulated fluxes, which are the weighted fraction average of fluxes from roads, walls, roofs, and natural surfaces.

consistent with the observations. In addition, simulated $Q_{E}$ is in good agreement with observations. The daily cycle of the storage heat flux for the urban surfaces is relatively well simulated by TEB, with the periods of heat uptake and heat release observed also simulated by the model (Fig. 9).

\section{Sensitivity studies}

\section{a. Source-area calculation}

To evaluate the effect of a static or dynamic modeling domain (section 5), all days of the observation campaign were classified in terms of wind conditions: mistral days, 
TABLE 4. Performance statistics for surface energy balance fluxes. Obs and TEB refer to the mean values for the period; bias $=$ TEB - obs; rmse is the root-mean-square error $\left(\mathrm{W} \mathrm{m}^{-2}\right)$.

\begin{tabular}{llrrrr}
\hline \hline \multirow{2}{*}{ Overall period } & & $Q^{*}$ & $Q_{H}$ & $Q_{E}$ & $\Delta Q_{S}$ \\
& Obs & 164 & 152 & 20 & -23 \\
& TEB & 148 & 129 & 14 & -10 \\
Daytime & Bias & -15 & -23 & -6 & +13 \\
& Rmse & 30 & 63 & 42 & 66 \\
& Obs & 374 & 247 & 31 & 93 \\
Nighttime & TEB & 354 & 221 & 28 & 103 \\
& Bias & -20 & -26 & -2 & +10 \\
& Rmse & 37 & 82 & 52 & 85 \\
& Obs & -69 & 48 & 11 & -126 \\
& TEB & -80 & 29 & 2 & -109 \\
& Bias & -11 & -19 & -9 & +17 \\
& Rmse & 19 & 31 & 31 & 44 \\
\hline
\end{tabular}

sea-breeze days, and other days without any special conditions. Source areas of the turbulent heat fluxes computed by the flux source area model (FSAM) (Schmid 1997) for the different conditions were determined (Fig. 10). Flux source areas are to the northwest of the tower during mistral winds and to the west and south during periods with pronounced sea breeze.

To produce the spatially most consistent comparison of modeled and measured fluxes, the modeling domain should be based on the flux source area for each time period of measurements. To achieve this, TEB simulations should be conducted for each high-resolution domain square $(i, j)$, forced by the tower atmospheric parameters. The turbulent fluxes $Q_{H}$ and $Q_{E}$ is the sum of the weighted $\left(w_{i, j}\right)$ fluxes for the instantaneous footprint:

$$
F_{\text {tower }}=\sum_{i, j} w_{i, j} F_{i, j} \text {. }
$$

Although this approach is computer intensive, the results can reveal whether the simulated turbulent fluxes are strongly modified by particular source-area footprint characteristics.

Given the high-resolution surface database developed for this study (see section 4), the TEB-ISBA input parameters of any part of the Marseille city center can be defined with a $10-\mathrm{m}$ horizontal resolution. The horizontal extent of the measurement source areas remain limited to the city center (see Fig. 10). As is evident from the aerial photograph (see Fig. 1), the surface characteristics are relatively homogeneous in this area. A sensitivity study over the range of conditions documented here can be used to evaluate the impact of dynamic modeling of source areas in central Marseille. If this impact is large, dynamic runs would be necessary.

Because the cover fractions are known for each source area, their variability can be computed. Five simulations $\left(S_{1}, S_{2}, S_{3}, S_{4}\right.$, and $\left.S_{5}\right)$ were run, modifying fractions of vegetation, roofs, and water by the quantity $\pm \sigma$ relative to the mean value of the fraction (see Table 5). When the vegetation or water fraction is modified (simulations $S_{1}, S_{2}$, and $S_{5}$ ), the inverse variation is applied

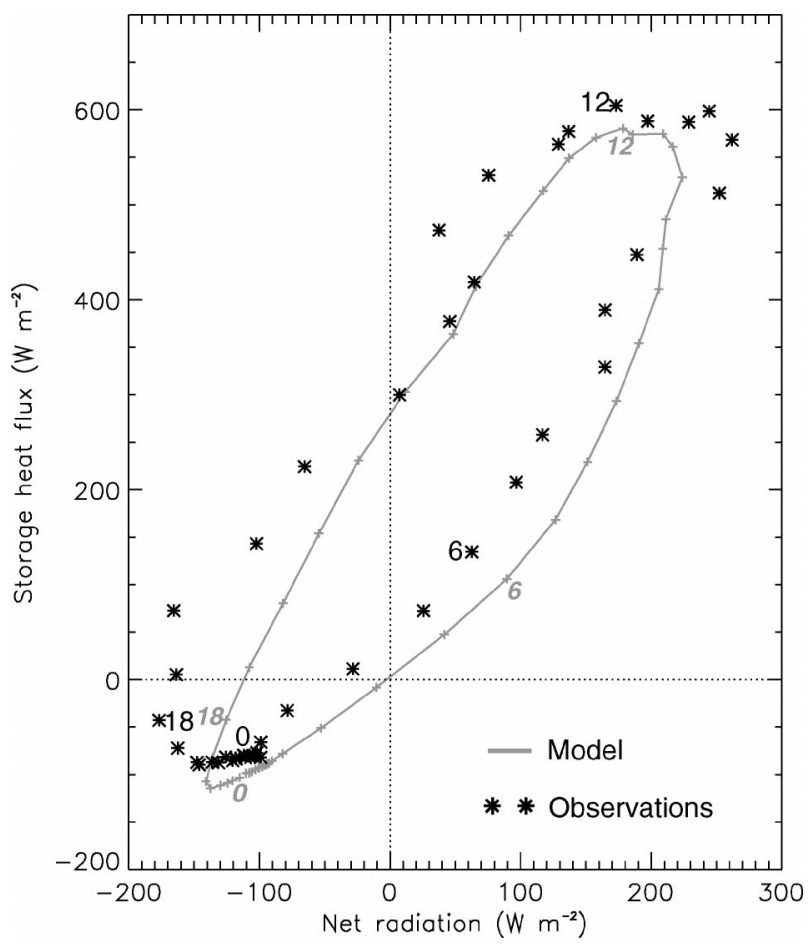

FIG. 9. Comparison between observed and simulated hysteresis loop relating the storage heat flux to the net radiation. The black asterisks and the gray line with pluses are the observations and the model outputs, respectively. The observed and simulated flux values at $0000,0600,1200$, and 1800 UTC are labeled.

to the town fraction. Thus, the roof fraction is modified too, but the ratio of roads and roofs is assumed constant. When the roof fraction is modified (simulations $S_{3}$ and $S_{4}$ ), the inverse variation is applied to the road fractions, while vegetation and water fractions stay the same. For two supplementary simulations $\left(S_{6}\right.$ and $\left.S_{7}\right)$, when the cover fractions were the same, the geometric parameters were modified by assuming a variation of $\pm 2.5 \mathrm{~m}$ on the mean building height. The aspect ratio of the canyon and the wall fraction were calculated again, according to the new building height values. Note that the cover fractions and the geometric parameters calculated for each sensitivity test stay constant for the entire period of the simulation. Table 5 gives, for each fraction cover case, the heat flux bias between the reference and the sensitivity case. The impact of the variations of the cover fractions and the geometric parameters on the fluxes computed by TEB is not very important (always under $\left.6 \mathrm{~W} \mathrm{~m}^{-2}\right)$. The strongest effect is found in simulation $\left(S_{5}\right)$ where the water fraction is increased. This corresponds to those periods when winds are from the northwest and the source area is influenced by the port (see Fig. 10). This condition actually only occurs for a relatively few 30-min periods during the measurement campaign. For the city center of Marseille, the relative homogeneity of the surface characteristics means that source-area calculations with the TEB scheme have lim- 


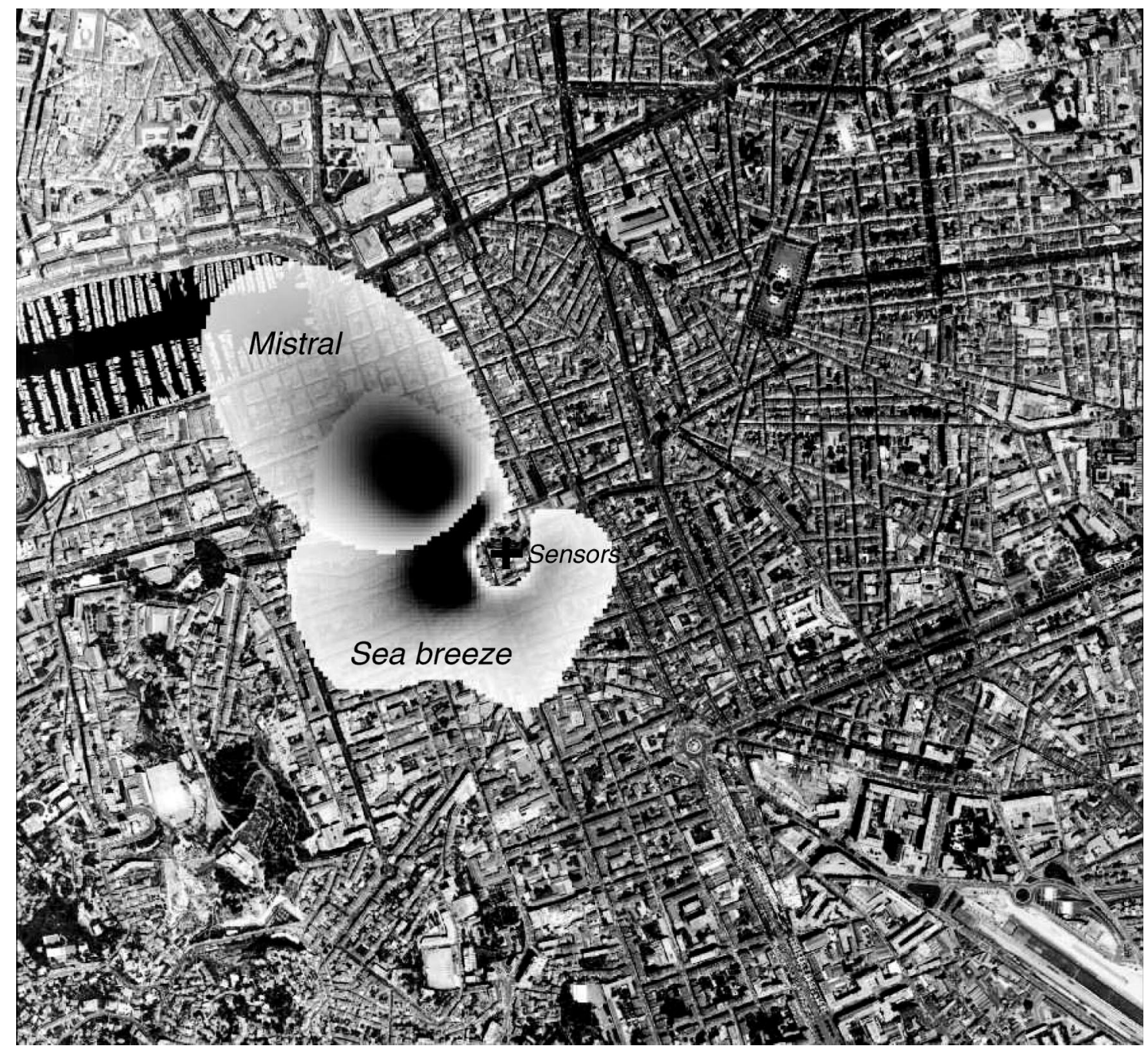

FIG. 10. Daytime source areas for the turbulent heat flux measurements for sea-breeze and mistral wind conditions. The darker areas have a more significant influence on the flux than the lighter areas. The areas shown are calculated for the $90 \%$ source area footprint for each 30 min of flux data under these wind conditions. The areas with greater than $0.01 \%$ influence are shown for each wind condition.

TABLE 5. Bias of simulated SEB fluxes to changes in surface fractions and geometric parameters. Bias $=$ reference (static model domain) - varied fraction of vegetation, roof, and water and geometric parameters $\left(\mathrm{W} \mathrm{m}^{-2}\right)$.

\begin{tabular}{lccc}
\hline \hline & & \multicolumn{2}{c}{ Bias } \\
\cline { 3 - 4 } \multicolumn{1}{c}{ Simulations } & New parameter & $Q_{H}$ & $Q_{E}$ \\
\hline S1: VEG+ & $f_{\text {veg }}=0.1870$ & -4.5 & +5.3 \\
S2: VEG - & $f_{\text {veg }}=0.0856$ & +4.5 & -5.3 \\
S3: ROOF+ & $f_{\text {roof }}=0.6685$ & +4.9 & +0.0 \\
S4: ROOF- & $f_{\text {roof }}=0.5209$ & +1.6 & +0.0 \\
S5: WATER + & $f_{\text {wat }}=0.0405$ & -5.7 & +0.3 \\
S6: HEIGHT + & $z_{\text {bld }}=18.1 \mathrm{~m}$ & -0.4 & +0.0 \\
S7: HEIGHT - & $z_{\text {bld }}=13.1 \mathrm{~m}$ & -0.7 & +0.0 \\
\hline
\end{tabular}

ited impact. The use of a static modeling domain is less computer intensive and sufficient for this case.

\section{b. Surface characterization}

Typically the surface database that is available to model large areas is not as detailed as that available in this study. Here we compare the results obtained using a readily available database with the site-specific database. In Europe, a commonly used source of surface information is the CORINE land cover classification (CEC 2000). This was used in 3D numerical simulations during anticyclonic conditions over Paris (Lemonsu and Masson 2002), where TEB is coupled to the Méso-NH atmospheric model. The CORINE database has a horizontal resolution of $250 \mathrm{~m}$ and distinguishes 11 urban classes within its 44 total classes, where the most common are urban dense, suburban, commercial, and in- 
TABLE 6. Cover fractions and TEB input parameters initialized according to the urban dense class of the CORINE land cover classification (Masson et al. 2003).

\begin{tabular}{|c|c|c|c|}
\hline \multicolumn{4}{|l|}{ Cover fractions } \\
\hline Natural cover & 0.100 & & \\
\hline Water & 0.000 & & \\
\hline \multirow{2}{*}{ Urban cover } & \multirow{2}{*}{0.900} & Building & 0.450 \\
\hline & & Road & 0.450 \\
\hline \multicolumn{4}{|l|}{ Geometric TEB parameters } \\
\hline Building height & \multicolumn{3}{|l|}{$30.0 \mathrm{~m}$} \\
\hline Canyon aspect ratio $z_{\mathrm{bld}} / W$ & \multicolumn{3}{|l|}{0.82} \\
\hline Wall/plane area ratio & \multicolumn{3}{|l|}{1.00} \\
\hline Roughness length for momentum $z_{0_{M}}$ & \multicolumn{3}{|l|}{$3.00 \mathrm{~m}$} \\
\hline \multicolumn{4}{|l|}{ Road properties } \\
\hline Albedo & \multicolumn{3}{|l|}{0.08} \\
\hline Emissivity & \multicolumn{3}{|l|}{0.94} \\
\hline \multicolumn{4}{|l|}{ Roof properties } \\
\hline Albedo & \multicolumn{3}{|l|}{0.15} \\
\hline Emissivity & \multicolumn{3}{|l|}{0.90} \\
\hline \multicolumn{4}{|l|}{ Wall properties } \\
\hline Albedo & \multicolumn{3}{|l|}{0.25} \\
\hline Emissivity & \multicolumn{3}{|l|}{0.82} \\
\hline
\end{tabular}

dustrial classes. For each class, Masson et al. (2003) have determined appropriate geometric parameters, thermal properties of materials, for use with the TEBISBA scheme. In reality, there are large differences in the materials and morphology both within and between urban areas.

The CORINE land cover classification, for the study area in Marseille, is composed of the urban dense class. The standard geometric parameters specified for this class (see Table 6) are different to those determined for Marseille in this study (Table 1), notably the aspect ratio. The SEB fluxes simulated with TEB-ISBA, using these surface data, are shown in Fig. 11 and are compared with those from the simulations above (with the more detailed averaged surface for the Marseille downtown site). The net radiation flux is better simulated in the TEB CORINE-based simulation, because the roof albedo used there is small (0.15). Nevertheless, this value is not in agreement with the measurements done in Marseille city center. For the TEB CORINE-based simulation, the turbulent and storage fluxes are correct (in term of bias, presented in Table 7) but with some discrepancies. The $Q_{H}$ is overestimated in the middle of the day and underestimated in the morning. In contrast, $\Delta Q_{S}$ is too large in the morning. The diurnal pattern of hysteresis is increased; the fluxes are shifted so that the maximum storage is observed earlier. These effects are directly induced by the modification of the aspect ratio of the street $z_{\text {bld }} / W$ and the decrease of the total wall area. In the same way, the perturbation affects the surface temperatures, which globally are overestimated (not shown). These results show that more specific knowledge of the surface characteristics of a city improves the simulated energy balance by TEB. In future 3D-modeling work on the ESCOMPTE domain, the pa-
TABLE 7. Performance statistics for SEB fluxes (Bias $=$ TEB obs) when CORINE (Masson et al. 2003) surface database is used for input parameters $\left(\mathrm{W} \mathrm{m}^{-2}\right)$.

\begin{tabular}{llrrrr}
\hline \hline \multirow{5}{*}{ Overall period } & & $Q^{*}$ & $Q_{H}$ & $Q_{E}$ & $\Delta Q_{S}$ \\
& Obs & 164 & 152 & 20 & -23 \\
& TEB & 168 & 157 & 10 & -11 \\
& Bias & +4 & +5 & -10 & +12 \\
Daytime & Rmse & 26 & 82 & 43 & 78 \\
& Obs & 374 & 247 & 31 & 93 \\
& TEB & 385 & 271 & 21 & 93 \\
Nighttime & Bias & +11 & +24 & -10 & -0 \\
& Rmse & 32 & 110 & 53 & 104 \\
& Obs & -69 & 48 & 11 & -126 \\
& TEB & -73 & 31 & 1 & -104 \\
& Bias & -5 & -17 & -9 & -22 \\
& Rmse & 18 & 30 & 31 & 43 \\
\hline
\end{tabular}

rameters determined in this study for Marseille city center will be applied to the urban dense class of the CORINE land cover classification.

\section{c. Soil water initialization}

The reference simulation assumes that all the natural covers of the Marseille city center are irrigated, because the water content of the ISBA hydrological layers is initialized to the field capacity (see Table 1). A complementary sensitivity test is conducted to estimate the impact of the soil water initialization on the energy fluxes. The water contents are initialized to the wilting point, namely, 0.213 instead of $0.302 \mathrm{~m}^{3} \mathrm{~m}^{-3}$. Under such condition, the latent heat flux is almost null (not shown). Because the net radiation is not significantly modified, the losses of latent heat flux are balanced by a sensible heat flux gain of about $50 \mathrm{~W} \mathrm{~m}^{-2}$. The heat storage is not influenced and does not change.

\section{Conclusions}

Running TEB in an offline mode, forced by towerbased measurements, allowed this study to focus on the influence of surface input parameters. Data collected on air temperatures within urban canyons allowed modeled and observed canyon air temperatures to be compared for the first time. The results showed that TEB in its original form did not simulate sufficiently rapid ventilation of the air from the canyon. When the mixing is intensified (but a very large $z_{0 M}$ I $z_{O H}$ ratio is kept for the whole urban domain), the simulated canyon air temperature is improved. The altered canyon aerodynamic resistance and the realistic definition of the TEB input parameters, resulted in good behavior in terms of road, wall, and roof surface temperatures and SEB fluxes.

The Marseille region is characterized by the presence of strong winds and large net radiative fluxes during summer. Under sea breeze conditions, a cold advection from the sea takes place and intensifies the temperature gradient between the ground and the atmosphere. As 

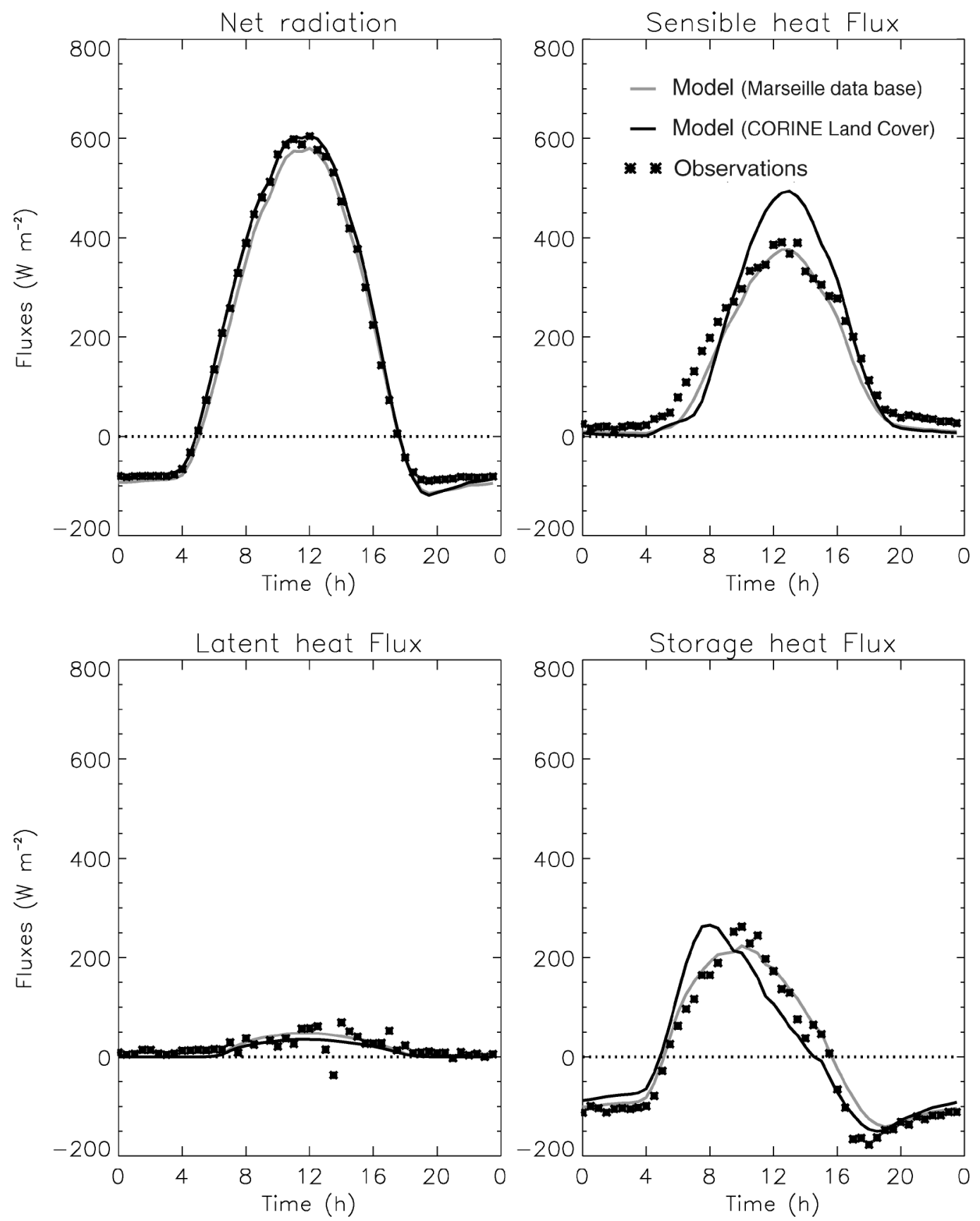

FIG. 11. Simulated and tower-based observed SEB fluxes. Simulations use the detailed surface database developed in this study (same as Fig. 8) and the CORINE (Masson et al. 2003) database.

a consequence, the partitioning between $Q_{H}$ and $\Delta Q_{S}$ favors the turbulent sensible heat flux. This is contrary to results from the Mexico City core, where TEB has been evaluated previously. In both cities, TEB-ISBA partitions these fluxes appropriately. Furthermore, at night, it succeeds in producing a positive $Q_{H}$, as observed in the measurements. All of these results are encouraging for future 3D modeling with TEB. Future research will involve high-resolution simulations with TEB-ISBA input parameters defined here for the city center, linked to the Méso-NH atmospheric model (Lafore et al. 1998).

Last, the sensitivity studies have shown that TEB is a robust surface scheme. The surface characteristics are sufficiently homogeneous to allow use of a static simulation domain. Nevertheless, the Marseille city 
center required specific attention, because their urban parameters are totally different than those usually applied to dense city centers.

Acknowledgments. The authors are very grateful to Joël Noilhan (CNRM, Météo-France), who is at the origin of this collaboration between CNRM and Indiana University. Thanks are extended to the following colleagues for providing data and their assistance: Dr. James Voogt (University of Western Ontario); Professor Timothy Oke, Sarah Roberts and Phoebe Jackson (University of British Columbia); Dr. Brian Offerle and Dr. Catherine Souch (Indiana University); Dr. Jennifer Salmond (University of Birmingham); Nathalie Long (Ecole Centrale of Nantes and the Siriatech society); Gregoire Pigeon (CNRM, Météo-France), Dr. Marc-André Velay-Dabat and Khrofa Lehtihet (Ecole d'Architecture de Marseille-Luminy); Dr. Dominique Groleau (Centre de Recherche Méthodologique d'Architecture, Ecole d'Architecture de Nantes); and Drs. Jean-Pierre Lagouarde and Mark Irvine (Institut National de la Recherche Agronomique de Bordeaux). They thank JeanFrançois Mauro from AIR-MARAIX (Marseille) for his help in the search of the measurement sites and thank the President of the CAA of Marseille. The ESCOMPTE-UBL project is funded by the CNRS programs for remote sensing from space (PNTS) and atmospheric dynamics (PATOM); Grimmond's participation was also supported by funding from the NSF (BCS-0095284).

\section{APPENDIX A}

\section{Application of the New Resistance Parameterization on Mexico City Downtown and Vancouver Light Industrial Sites}

In this study the Town Energy Balance has been modified to incorporate better venting of heat from the canyon. To ensure that this is not a site-specific improvement, the revised TEB model was also reevaluated for a downtown area of Mexico City and a light industrial site in Vancouver (described in Masson et al. 2002). For Mexico City, the impact of the modification is very small-almost nonexistent for road temperature (see Table A1) and for surface energy budget fluxes (see Table A2). This may be explained by the fact that sensible heat flux has a smaller role in Mexico City than in Marseille, and that there is a relatively small amount of

TABLE A1. Performance statistics for surface temperatures for Mexico City and Vancouver light industrial site with this study's version of TEB $(\mathrm{K})$.

\begin{tabular}{|c|c|c|c|c|c|}
\hline & \multicolumn{2}{|c|}{ Mexico City } & & \multicolumn{2}{|c|}{ Vancouver } \\
\hline & $\begin{array}{c}\text { Bias } \\
(\mathrm{TEB}-\mathrm{obs})\end{array}$ & Rmse & & $\begin{array}{c}\text { Bias } \\
(\mathrm{TEB}-\mathrm{obs})\end{array}$ & Rmse \\
\hline$T_{\text {road }}$ & +3.1 & 3.4 & $T_{\text {wall }}$ & -0.4 & 1.2 \\
\hline$T_{\text {roof }}$ & +1.9 & 4.5 & $T_{\text {roof }}$ & 2.4 & 7.4 \\
\hline
\end{tabular}

TABLE A2. Variation of heat fluxes between the initial simulation (Masson et al. 2002) and the simulation including the improvement of the canyon aerodynamic resistance (this work) for Mexico City and Vancouver light industrial sites $\left(\mathrm{W} \mathrm{m}^{-2}\right)$.

\begin{tabular}{lccc}
\hline \hline & $\Delta\left(Q^{*}\right)$ & $\Delta\left(Z_{H}+Q_{E}\right)$ & $\Delta\left(\Delta \mathrm{Q}_{S}\right)$ \\
\hline Mexico City & & & \\
Daytime & +4 & +15 & -11 \\
Nighttime & +2 & 0 & +2 \\
Vancouver & & & \\
Daytime & +5 & +13 & -8 \\
Nighttime & +2 & 1 & +3 \\
\hline
\end{tabular}

sunlight on roads for Mexico City, due to wintertime simulations (one can indeed note that the diurnal variation of road temperature is much smaller than for Marseille).

In contrast, for the Vancouver light industrial site, there is a major impact on surface temperatures (cf. Table 7 and Table 3 of Masson et al. 2002), with a large improvement of the wall surface temperature (bias is nearly removed and rmse is much smaller). This is due to the forcing of the wall surface temperature by a colder (and probably more appropriate) canyon air temperature. The variation of the energy fluxes, however, is not large, with mostly a small increase of sensible heat (approximately $5 \%$ ) in the daytime. Therefore, we conclude that the new form of TEB results in no impact for Mexico City and an improvement for the site in Vancouver.

\section{APPENDIX B}

\section{Calculation of the Wind Speed inside the Canyon}

The initial version of the calculation of the wind speed $U_{\text {can }}$ inside the canyon is presented in detail in Masson (2000). Generally, in the case where the mean flow above the roof level is parrallel to the canyon orientation, the wind speed is approximated by a logarithm profile between the high part of the canyon and the atmospheric level, while an exponential profile is imposed inside the canyon. In this parameterization, a zero $U_{\text {can }}$ is assumed when the mean flow is perpendicular to the canyon orientation. This assumption corresponds to the skimming flow (Oke 1987), where the urban canyons are narrow. Last, after integration on $360^{\circ}$ (in order to account for all street orientations), the $U_{\text {can }}$ expression is

$$
U_{\text {can }}=\frac{2}{\pi} \exp \left(-\frac{z_{\text {bld }}}{4 W}\right) \frac{\ln \left(\frac{z_{\text {bld }} / 3}{z_{0_{M} \text { town }}}\right)}{\ln \left(\frac{z_{\text {ref }}+z_{\text {bld }} / 3}{z_{0_{M} \text { town }}}\right)} U .
$$

An extension to the wake interference flow and the isolated roughness flow is now added in the calculation of the wind speed. When the canyon aspect ratio is larger than 1, the TEB parameterization stays unchanged [Eq. 
B1]. With an aspect ratio under 0.5 , namely, in the case of the isolated roughness flow, the wind speed inside the canyon keeps the same magnitude, whatever the orientation of the mean flow above the roof level:

$$
U_{\text {can }}=\exp \left(-\frac{z_{\text {bld }}}{4 W}\right) \frac{\ln \left(\frac{z_{\text {bld }} / 3}{z_{0_{M} \text { town }}}\right)}{\ln \left(\frac{z_{\text {ref }}+z_{\text {bld }} / 3}{z_{0_{M} \text { town }}}\right)} U .
$$

The intermediate case (corresponding to the wake flow) uses the followed formulation:

$$
\begin{aligned}
U_{\text {can }}= & {\left[1+2\left(\frac{2}{\pi}-1\right)\left(\frac{z_{\text {bld }}}{W}-\frac{1}{2}\right)\right] \exp \left(-\frac{z_{\text {bld }}}{4 W}\right) } \\
& \times \frac{\ln \left(\frac{z_{\text {bld }} / 3}{z_{0_{M} \text { town }}}\right)}{\ln \left(\frac{z_{\text {ref }}+z_{\text {bld }} / 3}{z_{0_{M} \text { town }}}\right)} U .
\end{aligned}
$$

\section{APPENDIX C}

\section{Calculation of the Global Urban Albedo}

From the incoming shortwave radiation $\left(S^{\downarrow}\right)$, TEB calculates the fraction of incident shortwave radiation absorbed by built surfaces. It takes into account the 3D urban geometry to estimate the shade effects, radiation trapping, and absorption, according to the following (Masson 2000):

$$
\begin{aligned}
S_{\text {road }}^{*}= & \left(1-\alpha_{\text {road }}\right) S_{\text {road }}^{\Downarrow}+\left(1-\alpha_{\text {road }}\right) S_{\text {road }}^{\downarrow} \\
& +\left(1-\alpha_{\text {road }}\right)\left(1-\Psi_{\text {road }}\right) M_{\text {wall }}^{S \uparrow}, \text { and } \\
S_{\text {wall }}^{*}= & \left(1-\alpha_{\text {wall }}\right) S_{\text {wall }}^{\Downarrow}+\left(1-\alpha_{\text {wall }}\right) S_{\text {wall }}^{\downarrow} \\
& +\left(1-\alpha_{\text {wall }}\right)\left(1-2 \Psi_{\text {wall }}\right) M_{\text {wall }}^{S \uparrow} \\
& +\left(1-\alpha_{\text {wall }}\right)\left(1-\Psi_{\text {wall }}\right) M_{\text {road }}^{S \uparrow}, \quad \text { and } \\
S_{\text {roof }}^{*}= & \left(1-\alpha_{\text {roof }}\right) S_{\text {roof }}^{\Downarrow}+\left(1-\alpha_{\text {roof }}\right) S_{\text {roof }}^{\downarrow},
\end{aligned}
$$

where $\alpha_{i}$ are the road, wall, and roof albedos; $S_{i}^{\Downarrow}$ and $S_{i}^{\downarrow}$ are the direct and scattered solar radiation received by roads, walls, and roofs; $\Psi_{i}$ are the road and wall sky-view factors; and $M_{i}^{s \uparrow}$ is the energy absorbed from all the reflected radiation:

$$
\begin{aligned}
M_{\text {road }}^{S \uparrow} & =S_{\text {road }}^{\uparrow}(0)+\frac{\left(1-\Psi_{\text {road }}\right) \alpha_{\text {road }}\left[S_{\text {wall }}^{\uparrow}(0)+\Psi_{\text {wall }} \alpha_{\text {wall }} S_{\text {road }}^{\uparrow}(0)\right]}{1-\left(1-2 \Psi_{\text {wall }}\right) \alpha_{\text {wall }}-\left(1-\Psi_{\text {road }}\right) \Psi_{\text {wall }} \alpha_{\text {road }} \alpha_{\text {wall }}} \text { and } \\
M_{\text {wall }}^{S \uparrow} & =\frac{S_{\text {wall }}^{\uparrow}(0)+\Psi_{\text {wall }} \alpha_{\text {wall }} S_{\text {road }}^{\uparrow}(0)}{1-\left(1-2 \Psi_{\text {wall }}\right) \alpha_{\text {wall }}-\left(1-\Psi_{\text {road }}\right) \Psi_{\text {wall }} \alpha_{\text {road }} \alpha_{\text {wall }}}
\end{aligned}
$$

The reflected radiation at first reflection $S_{i}^{\uparrow}(0)$ are defined in Masson (2000) as $R_{i}(0)$ (notation has been clarified here). The outgoing shortwave radiation can be resolved separately for roads, walls, and roofs, and averaged according to the respective fractions of area covers. Last, the global urban albedo is defined as the ratio of total outgoing and incoming shortwave radiation:

$$
\alpha_{\text {TEB }}=1-\frac{f_{\text {road }} S_{\text {road }}^{*}+f_{\text {wall }} S_{\text {wall }}^{*}+f_{\text {roof }} S_{\text {roof }}^{*}}{f_{\text {road }}\left(S_{\text {road }}^{\Downarrow}+S_{\text {road }}^{\downarrow}\right)+f_{\text {wall }}\left(S_{\text {wall }}^{\Downarrow}+S_{\text {wall }}^{\downarrow}\right)+f_{\text {roof }}\left(S_{\text {roof }}^{\Downarrow}+S_{\text {roof }}^{\downarrow}\right)},
$$

with $f_{\text {road }}, f_{\text {wall }}$, and $f_{\text {roof }}$ being the respective fractions of roads, walls, and roofs.

\section{REFERENCES}

ASHRAE, 1981: ASHRAE Handbook: 1981 Fundamentals. American Society of Heating, Refrigering and Air-Conditioning Engineers, Inc., $800 \mathrm{pp}$.

Baik, J.-J., and J.-J. Kim, 2002: On the escape of pollutants from urban street canyons. Atmos. Environ., 36, 527-536.

Barlow, J. F., and S. E. Belcher, 2002: A wind tunnel model for quantifying fluxes in the urban boundary layer. Bound.-Layer Meteor., 104, 131-150.
Best, M. J., 1998: A model to predict surface temperatures. Bound.Layer Meteor., 88, 279-306.

Bornstein, R., 1975: The two-dimensional URBMET boundary layer model. J. Appl. Meteor., 14, 1459-1477.

Brown, M. J., 2000: Urban parameterizations for mesoscale meteorological models. Mesoscale Atmospheric Dispersion, Z. Boybeyi, Ed., Wessex Press, 193-255.

CEC, 2000: CORINE land cover technical guide-Addendum 2000. European Environment Agency Tech. Rep. 40, 105 pp.

Christen, A., R. Vogt, M. Rotach, and E. Parlow, 2002: First results from BUBBLE II: Partioning of turbulent heat fluxes over urban surfaces. Preprints, Fourth Symp. on the Urban Environment, Norfolk, VA, Amer. Meteor. Soc., 137-138.

Cleugh, H. A., and T. R. Oke, 1986: Suburban-rural energy balance 
comparisons in summer for Vancouver, B.C. Bound.-Layer Meteor., 36, 351-369.

Cros, B., and Coauthors, 2002: The ESCOMPTE Program: An overview. Atmos. Res., in press.

EDF, and Atelier du patrimoine de la ville de Marseille, 1983: Le Bâti Ancien à Marseille. Connaissance de l'habitat existant, Electricité de France, 144 pp.

Grimmond, C. S. B., 1992: The suburban energy balance: Methodological considerations and results for a mid-latitude west coast city under winter and spring conditions. Int. J. Climatol., 12, 481-497.

—_, and T. R. Oke, 1991: An evapotranspiration-interception model for urban areas. Water Resour. Res., 27, 1739-1755.

$\ldots$, and —_, 1995: Comparison of heat fluxes from summertime observations in the suburbs of four North American cities. $J$. Appl. Meteor., 34, 873-889.

$\longrightarrow$, and — 1999a: Aerodynamic properties of urban areas derived from analysis of surface form. J. Appl. Meteor., 38, 12621292.

$\longrightarrow$, and - 1999b: Heat storage in urban areas: Local-scale observations and evaluation of a simple model. J. Appl. Meteor. 38, 922-940.

— J. Salmond, B. D. Offerle, and T. R. Oke, 2002: Local-scale surface flux measurements at a downtown site in Marseille during the ESCOMPTE field campaign. Preprints, Fourth Symp. on the Urban Environment, Norfolk, VA, Amer. Meteor. Soc., 2122.

Johnson, G. T., and L. J. Hunter, 1995: A numerical study of dispersion of passive scalars in city canyons. Bound.-Layer Meteor., 75, 235-262.

Kim, J.-J., and J.-J. Baik, 1999: A numerical study of thermal effects on flow and pollutant dispersion in urban street canyons. J. Appl. Meteor., 38, 1249-1261.

Lafore, J. P., and Coauthors, 1998: The Méso-NH atmospheric simulation system. Part I: Adiabatic formulation and control simulation. Ann. Geophys., 16, 90-109.

Lagouarde, J. P., M. Irvine, J. M. Bonnefond, C. S. B. Grimmond, N. Long, T. R. Oke, J. Salmond, and B. Offerle, 2002: Sensible heat flux estimated over the city of Marseille, using a LAS scintillometer. Preprints, Fourth Symp. on the Urban Environment, Norfolk, VA, Amer. Meteor. Soc., 215-216.

Lemonsu, A., and V. Masson, 2002: Simulation of a summer urban breeze over Paris. Bound.-Layer Meteor., 104, 463-490.

Long, N., P. Mestayer, and C. Kergomard, 2002: Development of a software to describe the city morphology and to compute aerodynamic parameters from an urban data base. Preprints, Fourth Symp. on the Urban Environment, Norfolk, VA, Amer. Meteor. Soc., 31-32.

Martilli, A., A. Clappier, and M. W. Rotach, 2002: An urban surface exchange parameterization for mesoscale models. Bound.-Layer Meteor., 104, 261-304.

Mascart, P., J. Noilhan, and H. Giordani, 1995: A modified parameterization of flux-profile relationship in the surface layer using different roughness length values for heat and momentum. Bound.-Layer Meteor., 72, 331-344.

Masson, V., 2000: A physically-based scheme for the urban energy budget in atmospheric models. Bound.-Layer Meteor., 94, $357-$ 397.

, C. S. B. Grimmond, and T. R. Oke, 2002: Evaluation of the
Town Energy Balance (TEB) scheme with direct measurements from dry districts in two cities. J. Appl. Meteor., 41, 1011-1026. - J. L. Champeaux, F. Chauvin, C. Meriguet, and R. Lacaze, 2003: A global database of land surface parameters at $1-\mathrm{km}$ resolution in meteorological and climate models. J. Climate, 16, 1261-1282.

McMullan, R., 1992: Environmental Science in Building. 3d ed. Macmillan Press Ltd., 332 pp.

Mestayer, P., and Coauthors, 2003: The urban boundary layer field experiment over Marseille. UBL/CLU-ESCOMPTE: Experimental set-up and first results. Bound.-Layer Meteor., in press.

Mills, G. M., 1993: Simulation of the energy budget of an urban canyon-I: Model structure and sensitivity test. Atmos. Environ., 27B, 157-170.

Monin, A. S., and A. M. Obukhov, 1954: The main features of turbulent mixing in the surface atmospheric layer. Tr. Inst. Geofiz. Akad. Nauk. SSSR, 151, 163-187.

Nakamura, Y., and T. R. Oke, 1988: Wind, temperature and stability conditions in an east-west oriented urban canyon. Atmos. Environ., 22, 2691-2700.

Noilhan, J., and S. Planton, 1989: A simple parameterization of land surface processes for meteorological models. Mon. Wea. Rev., 117, 536-549.

_ , and J. F. Mahfouf, 1996: The ISBA land surface parameterisation scheme. Global Planet. Change, 13, 145-159.

Offerle, B., C. S. B. Grimmond, K. Fortuniak, T. R. Oke, and K. Klysik, 2002: Analysis of long-term observations of urban surface-atmosphere energy exchange. Preprints, Fourth Symp. on the Urban Environment, Norfolk, VA, Amer. Meteor. Soc., 103104.

Oke, T. R., 1987: Boundary Layer Climates. 2d ed. Methuen, 435 pp.

R. A. Spronken-Smith, E. Jáuregui, and C. S. B. Grimmond, 1999: The energy balance of central Mexico City during the dry season. Atmos. Environ., 33, 3919-3930.

Pigeon, G., A. Lemonsu, P. Durand, and V. Masson, 2002: Urban surface network in Marseille: Network optimization using numerical simulations and results. Preprints, Fourth Symp. on the Urban Environment, Norfolk, VA, Amer. Meteor. Soc., 23-24.

Rotach, M., 2002: Overview on the Basel Urban Boundary Layer Experiment-BUBBLE. Preprints, Fourth Symp. on the Urban Environment, Norfolk, VA, Amer. Meteor. Soc., 25-26.

Roth, M., and T. R. Oke, 1995: Relative efficiencies of turbulence transfer of heat, mass and momentum over a patchy urban surface. J. Atmos. Sci., 52, 1863-1874.

Schmid, H. P., 1997: Experimental design for flux measurements: Matching scales of observations and fluxes. Bound.-Layer Meteor., 87, 179-200.

_ _ and T. R. Oke, 1990: A model to estimate the source area contributing to turbulent exchange in the surface layer over patchy terrain. Quart. J. Roy. Meteor. Soc., 116, 965-988.

Taha, H., 1999: Modifying a mesoscale meteorological model to better incorporate urban heat storage: A bulk parametrerization approach. J. Appl. Meteor., 38, 466-473.

Vachon, G., 2001: Transferts des polluants des sources fixes et mobiles dans la canopé urbaine: Evaluation expérimentale. Ph.D. thesis, University of Nantes, $210 \mathrm{pp}$.

Voogt, J. A., and C. S. B. Grimmond, 2000: Modeling surface sensible heat flux using surface radiative temperatures in a simple urban area. J. Appl. Meteor., 39, 1679-1699. 